\title{
Association between parental motives for food choice and eating patterns of 12- to 13-year-old Norwegian children
}

\author{
Inger M Oellingrath ${ }^{1, *}$, Margrethe Hersleth ${ }^{2}$ and Martin V Svendsen ${ }^{3}$ \\ ${ }^{1}$ Faculty of Health and Social Sciences, Department of Health Studies, Telemark University College, PO Box 201, \\ 3914 Porsgrunn, Norway: ${ }^{2}$ Nofima - Norwegian Institute of Food, Fisheries and Aquaculture Research, Ås, \\ Norway: ${ }^{3}$ Department of Occupational and Environmental Medicine, Telemark Hospital, Skien, Norway
}

Submitted 20 March 2012: Final revision received 13 July 2012: Accepted 21 August 2012: First published online 4 0ctober 2012

\begin{abstract}
Objective: To determine (i) the importance of parents' motives for everyday family food choices; and (ii) the relationship between parental food choice motives and eating patterns of 12- to 13-year-old children.

Design: Cross-sectional study. A modified version of the Food Choice Questionnaire was used to determine parental motives for food choices. The children's food and drink intake was reported by their parents using a retrospective FFQ. Eating patterns were derived using principal component analysis. The association between food choice motives and eating patterns was examined using multiple linear regression analysis.

Setting: Primary schools, Telemark County, Norway.

Subjects: In total, 1095 children aged 12-13 years and their parents.

Results: The parental motive 'sensory appeal' was the most important for food choice, followed by 'health', 'convenience', 'natural content' and 'weight control'. The food choice motives were associated with the eating patterns of the children, independent of background variables. The motive 'health' was most strongly associated with a 'varied Norwegian' eating pattern, representing a diverse diet and regular meals, while the motive 'convenience' appeared to be the most important barrier to this eating pattern. 'Weight control' was not associated with the 'varied Norwegian' eating pattern.

Conclusions: To encourage parents to make healthy food choices for their children, health promotion activities should focus on the health benefits of a diverse diet and regular meals, rather than weight control. Recommended food products should be made more convenient and easily available for families with children.
\end{abstract}

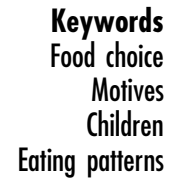

Dietary choice may have important consequences for health $^{(1)}$. Of particular concern are unhealthy diets and energy imbalances in children and adolescents ${ }^{(2)}$, as overweight and obesity in young people may have adverse consequences on physical morbidity in adulthood and result in premature mortality ${ }^{(3)}$. National studies among 8- to 13-year-old Norwegian children show a lower intake of fruit and vegetables and a higher intake of sugar than the official dietary recommendations ${ }^{(4)}$. Furthermore, a substantial increase in overweight has been observed in Norwegian schoolchildren over the last 30 years $^{(5,6)}$. One priority of the Norwegian health authorities is to improve the eating habits of children by recommending regular meals and a diverse diet high in fibre and low in energy-dense products.

Personal food choices are influenced by a wide spectrum of social, cultural and individual factors ${ }^{(7-9)}$. At the individual level, the motivation for food choice may be influenced by factors like sensory appeal, convenience, price, habit, weight control, health concerns and ethical concerns. These factors have also been associated with diet quality in adults, and may explain differences in diet linked to socio-economic status ${ }^{(8,10-15)}$. Individual motives are considered to be modifiable and therefore interesting with regard to health promoting activities. The Food Choice Questionnaire (FCQ) has been developed ${ }^{(8)}$ to assess the motives underlying individual food selection. The FCQ is a multidimensional measure of thirty-six statements relevant to consumers' food choices.

Parents play a primary role in providing food for their children. The family eating environment, including parental food attitudes, eating behaviour and feeding practices, is central in the development of children's eating habits and weight outcome ${ }^{(16-20)}$. However, few studies have examined the relationship between parental food choice motives and children's dietary habits ${ }^{(21,22)}$. As available data are limited, and the importance of motives may vary between countries and cultures ${ }^{(23,24)}$, additional 
studies are needed. Norwegian studies of food choice motives have thus far focused on adult consumers' motives for selecting foods with certain characteristics ${ }^{(25,26)}$, not on the association between parental food choice motives and children's diets.

We have previously reported four distinct eating patterns among primary-school children in Telemark County, Norway, representing both healthy and unhealthy eating habits ${ }^{(27,28)}$. Parental-reported food choice motive data were collected simultaneously at age $12-13$ years. The aims of the present study were to: (i) determine parents' motives for everyday family food choices; and (ii) investigate the relationship between parental food choice motives and the eating patterns of 12- to 13-year-old children.

\section{Methods}

\section{Participants and study design}

The present data were obtained from a study of diet, physical activity and BMI development in primary-school children in Telemark County, Norway. The data were collected in the spring of 2010, from children in primary school grade 7 (age 12-13 years). The detailed data collection methods have been described previously ${ }^{(27,28)}$. In brief, all 104 primary schools in Telemark County were invited to participate in the study, and fifty-three agreed. Written parental consent to inclusion in the study was received for 1095 out of 1503 invited children, representing about half of the county's grade 7 pupils. Complete data on parental-reported food choice motives and children's diet were obtained for 786 participants. The study was conducted according to the guidelines laid down in the Declaration of Helsinki and the research protocol was approved by the Regional Committee for Ethics in Medical Research and the Norwegian Data Inspectorate. Informed written consent was obtained from the parents of all participating children.

\section{Food choice motives}

Parental motives for food choices were measured using statements from the original $\mathrm{FCQ}^{(8)}$. The original FCQ contained a total of thirty-six statements covering health, mood, convenience, sensory appeal, natural content, price, weight control, familiarity and ethical concerns. After considering the relevance of the different items in the present study, we decided to make the following adjustments: (i) reduce the number of items in the original study's mood dimension from six to three; (ii) omit one statement from the original study's ethical concern dimension; and (iii) add an extra statement - 'is low in sugar' - to reflect that the amount of sugar in the diet is an important nutritional issue (Table 1). Accordingly, the parents were presented with thirty-three statements in total (Table 1). All statements had previously been translated into Norwegian using the back-translation procedure 29,30$)$ as part of the TRUEFOOD pan-European consumer study $^{(31)}$. To make the respondents focus on the family diet, the parents were asked to endorse the statement 'It is important to me that the food we eat on a typical day...', instead of '...the food $I$ eat...', as in the original questionnaire. To ensure a focus on family diet, the FCQ was presented to the parents after the dietary data. Instead of the original four-category scale ${ }^{(8)}$, a seven-point Linkert scale was used to increase the variability of the measurement scale and thereby allow for better discrimination ${ }^{(7)}$. The response alternatives ranged from $1=$ 'I totally disagree' through $4=$ 'I neither agree nor disagree' to $7=$ 'I totally agree'. Complete food choice motive data were obtained for 840 participants.

\section{Dietary information}

The children's food and drink intake was reported by their parents using a retrospective FFQ, which asked about habitual daily consumption of forty food items, eleven types of drink, thirteen types of snacks (between meals) and five main meals (breakfast, lunch, afternoon meal, dinner, supper) during the last 6 months. This questionnaire was based on a short FFQ developed for use with children in grades 4 and 8 in Norway, but was modified to include more dietary questions. Before the study, the FFQ was tested on a sample of parents and followed up by qualitative interviews ${ }^{(32)}$. Response alternatives and other details have been reported previously ${ }^{(28)}$. Complete dietary data were obtained for 800 participants.

\section{Socio-economic variables}

In addition to providing dietary information and motives for food choice, the parents reported their educational level and family income.

Parental educational level was divided into three categories: 'primary/lower secondary education' (10 years or less), 'upper secondary education' (3 to 4 years) and 'university or university college'.

Family income was divided into three categories: 'both parents <NOK 300000 ( $€ 33$ 909)', 'one parent $\geq$ NOK 300000 ' and 'both parents $\geq$ NOK 300000 ', where NOK is Norwegian kroner.

\section{BMI categories of children and parents}

The weight and height of the children were measured by public health nurses at each school. The children were weighed wearing light clothing (i.e. trousers, T-shirt, socks) using calibrated, electronic scales measuring in $100 \mathrm{~g}$ increments. The BMI $\left(\mathrm{kg} / \mathrm{m}^{2}\right)$ of each child was calculated based on these measurements. Child BMI categories were calculated using the International Obesity Taskforce cut-off points (underweight, normal weight, overweight, obese), based on growth curves and BMI values of 17,25 and $30 \mathrm{~kg} / \mathrm{m}^{2}$ at age 18 years ${ }^{(33,34)}$. The respective cut-off points for $12 \cdot 5$-year-old boys and girls were used. Due to small numbers, we included 
Table 1 Summary of initial PCA of current parental food choice statements (varimax rotation, factor loadings $>0 \cdot 45$ ). Parents of children aged 12-13 years, Telemark County, Norway, 2010

\begin{tabular}{|c|c|c|c|c|c|c|c|c|}
\hline \multirow[b]{2}{*}{ Food choice statement } & \multicolumn{8}{|c|}{ Dimension number } \\
\hline & $1^{*}$ & 2 & 3 & 4 & 5 & 6 & 7 & 8 \\
\hline Contains a lot of vitamins and minerals & $0 \cdot 76$ & & & & & & & \\
\hline Contains no artificial ingredients & 0.73 & & & & & & & \\
\hline Is nutritious & $0 \cdot 70$ & & & & & & & \\
\hline Contains natural ingredients & $0 \cdot 70$ & & & & & & & \\
\hline Is high in protein & $0 \cdot 67$ & & & & & & & \\
\hline Contains no additives & 0.66 & & & & & & & \\
\hline Is high in fibre and roughage & 0.64 & & & & & & & \\
\hline Is packaged in an environmentally friendly way & 0.60 & & & & & & & \\
\hline Is good for my skin/teeth/hair/nails & 0.59 & & & & & & & \\
\hline Keeps me healthy & 0.58 & & & & & & & \\
\hline Has the country of origin clearly marked & 0.53 & & & & & & & \\
\hline Is low in sugart & 0.52 & & & & & & & \\
\hline Cheers me up & & $0 \cdot 75$ & & & & & & \\
\hline Helps me cope with stress & & 0.67 & & & & & & \\
\hline Makes me feel good & & 0.62 & & & & & & \\
\hline Has a pleasant texture & & $0 \cdot 60$ & & & & & & \\
\hline Takes no time to prepare & & & $0 \cdot 89$ & & & & & \\
\hline Can be cooked very simply & & & 0.85 & & & & & \\
\hline Is easy to prepare & & & 0.82 & & & & & \\
\hline Is easily available in shops and supermarkets & & & & & & & & $0 \cdot 60$ \\
\hline Can be bought in shops close to where I live/work & & & & & & & & 0.51 \\
\hline Is low in fat & & & & $0 \cdot 82$ & & & & \\
\hline Is low in calories & & & & $0 \cdot 80$ & & & & \\
\hline Helps me control my weight & & 0.51 & & $0 \cdot 61$ & & & & \\
\hline Tastes good & & & & & $0 \cdot 74$ & & & \\
\hline Looks nice & & & & & $0 \cdot 65$ & & & \\
\hline Smells nice & & 0.54 & & & 0.57 & & & \\
\hline Is what I usually eat & & & & & & $0 \cdot 76$ & & \\
\hline Is like the food I ate as a child & & & & & & $0 \cdot 70$ & & \\
\hline Is familiar & & & & & & 0.56 & & \\
\hline Is not expensive & & & & & & & $0 \cdot 75$ & \\
\hline Is cheap & & & & & & & 0.69 & \\
\hline Offers good value for money & & & & & & & 0.54 & \\
\hline Helps me cope with lifeł & & & & & & & & \\
\hline Helps me relax & & & & & & & & \\
\hline Keeps me awake/alertł & & & & & & & & \\
\hline Comes from countries I approve of politically & & & & & & & & \\
\hline
\end{tabular}

PCA, principal component analysis; FCQ, Food Choice Questionnaire.

*When statements from dimension 1 were entered into a separate PCA, they emerged in three sub-dimensions related to health, natural content and ethic concerns, respectively (data not shown).

tStatement not included in the original FCQ.

$\ddagger$ Statements from the original FCQ omitted in the current, modified FCQ.

underweight children in the normal-weight group and obese children in the overweight group.

Parent BMI categories were calculated based on self-reported height and weight and the International Obesity Taskforce cut-off points for adults (overweight at $\mathrm{BMI} \geq 25 \mathrm{~kg} / \mathrm{m}^{2}$ ).

\section{Statistical analyses}

An initial principal component analysis (PCA) was performed to investigate whether the same motive dimensions were valid in our sample as in the original $\mathrm{FCQ}^{(8)}$. Motive scores were calculated as the mean of the underlying statement scores for each respondent and used as continuous variables in the further analyses. A high motive score indicates high importance of the respective food choice motive, while a lower mean score indicates lower importance. Cronbach's alpha $(\mathrm{Cr} \alpha)$ was used as a measure of the internal reliability of each motive. Food choice motives with poor or unacceptable internal reliability $(\mathrm{Cr} \alpha \leq 0 \cdot 70)^{(35)}$ were omitted from the further analyses.

Four distinct eating patterns had previously been identified from the reported dietary responses using $\mathrm{PCA}^{(28,36)}$. The eating patterns were named after the nature of the foods, beverages and meals within each pattern, as follows: (i) a 'junk/convenient' pattern, characterised by processed fast foods with high fat and sugar content; (ii) a 'varied Norwegian' pattern, characterised by regular main meals and a diverse diet, close to what is recommended by the health authorities; (iii) a 'snacking' pattern, characterised by snack items, sugar-sweetened drinks and irregular main meals; and, finally, (iv) a 'dieting' pattern, containing foods and drinks often associated with dieting and weight control, like artificially sweetened and low-fat products. Individuals were given 
factor scores for each of the eating patterns. Positive factor scores indicate high consumption of foods, drinks, snacks and meals within the respective pattern, while negative factor scores indicate low consumption. The factor scores for each eating pattern were used as continuous variables in the present regression analysis.

We used a multiple linear regression model to examine the association between food choice motives and eating patterns as independent and dependent variables, respectively. The potential confounding background variables available for the multiple regression analysis were child's gender, child's overweight, maternal and paternal overweight, maternal and paternal education, and total family income. We employed a stepwise selection that included the variables significantly associated with eating patterns in each model. Adjusting for all of the background variables had little additional impact on the effect estimates.

Only participants for whom complete data on food choice statements and dietary responses were available ( $n$ 786) were used in the present analyses. The categorical background variables were constructed as dummy variables before being entered in the regression model.

For all tests, a significance level of $P<0.05$ was applied. The questionnaires were scanned by Eyes and Hands (Readsoft Forms, Helsingborg, Sweden), and all statistical analyses were carried out using the SPSS statistical software package version 15 .

\section{Results}

Of the 786 participants included in the analyses, 50\% were boys and $50 \%$ were girls. Some $52 \%$ of mothers and $39 \%$ of fathers were registered in the highest education category, 'university or university college', while $36 \%$ of mothers and $48 \%$ of fathers fell into the category 'upper secondary education' and $12 \%$ of mothers and 13\% of fathers fell into the lowest education category - 'primary/ lower secondary education'. In total, $89 \%$ of the parents were registered in the two highest categories of family income. Furthermore, $16 \%$ of the children (objective measures), $36 \%$ of mothers and $53 \%$ of fathers (selfreported data) were registered as overweight.

The initial PCA identified eight motive dimensions (Table 1). Dimension 1 included statements concerning health, natural content and ethical concerns. When the statements of dimension 1 were analysed in a separate PCA, three distinct patterns related to health, natural content and ethical concerns emerged (data not shown). Dimension 2 included statements related to personal mood and emotion. Two statements related to sensory quality and one statement related to personal weight control also emerged in this dimension. Dimensions 3 and 8 respectively included statements related to convenient cooking and food availability. Dimensions 4, 5, 6 and 7 included statements related to weight control, sensory quality, familiarity and price.

We decided to use the original dimensions ${ }^{(8)}$ to calculate food choice motives and labelled them accordingly. The internal reliability of the current food choice motives ( $\mathrm{Cr} \alpha$ ) ranged from 0.55 to 0.84 (Table 2 ). The motives 'price', 'ethical concerns' and 'familiarity' were omitted from the regression analyses due to poor or unacceptable internal reliability $(\mathrm{Cr} \alpha \leq 0 \cdot 70)^{(35)}$. The food choice motive 'sensory appeal' was found to be the most important motive behind everyday parental food choices, followed by the motives 'health', 'convenience', 'natural content' and 'weight control' (Table 2). The motives 'mood', 'price' and 'ethical concerns' were of less importance, and the motive 'familiarity' was rated least important by the parents (Table 2). The ranking order of the food choice motives was determined independently of socio-economic background and BMI of the parents and children (data not shown).

Multiple regression analysis of the associations between parental food choice motives and children's eating patterns (Table 3) showed that the strongest associations appeared between the motive 'health' and the 'varied Norwegian' eating pattern, and between the motive 'weight control' and the 'dieting' pattern. In addition, negative associations were observed between both the 'health' (strongest association) and 'weight control' motives and the 'junk/convenient' eating pattern. Negative association was also evident between the 'weight control' motive and the 'snacking' pattern. The 'mood' motive was positively associated with the 'junk/ convenient' pattern and the 'snacking' pattern, while 'convenience' was positively correlated with the 'junk/ convenient' pattern and negatively associated with the 'varied Norwegian' eating pattern. 'Sensory appeal' and 'natural content' were negatively associated with the 'dieting' pattern, while 'natural content' was positively associated with the 'varied Norwegian' eating pattern. All associations were observed independently of available background variables (Table 3, adjusted model).

\section{Discussion}

In the present study, 'sensory appeal' emerged as the most important motive for food choice, followed by 'health', 'convenience' and 'natural content' (Table 2). Although country-specific consumer differences are evident ${ }^{(23,24)}$, several other studies have identified the same four motives as being among the most important for individual food choice ${ }^{(8,10,21)}$. 'Sensory appeal' has been identified as the most important motive in previous studies ${ }^{(25,37)}$ and is based on statements related to 'smell', 'appearance', 'texture' and 'taste'. However, to be able to market healthy food, additional studies are needed on what 'sensory appeal' means to children and adults respectively. 
Table 2 Parental food choice motives ( $n 786$ ) including thirty-three individual statements, calculated motive scores, standard deviation and internal reliability (Cronbach's alpha, $\mathrm{Cr} \alpha$ ). Parents of children aged 12-13 years, Telemark County, Norway, 2010

\begin{tabular}{|c|c|c|c|}
\hline Food choice motives & Motive score & SD & $\operatorname{Cr} \alpha$ \\
\hline $\begin{array}{l}\text { 'Sensory appeal' } \\
\text { Smells nice } \\
\text { Looks nice } \\
\text { Has a pleasant texture } \\
\text { Tastes good }\end{array}$ & $5 \cdot 7$ & 0.9 & $0 \cdot 74$ \\
\hline $\begin{array}{l}\text { 'Health' } \\
\text { Contains a lot of vitamins and minerals } \\
\text { Keeps me healthy } \\
\text { Is nutritious } \\
\text { Is high in protein } \\
\text { Is good for my skin/teeth/hair/nails } \\
\text { Is high in fibre and roughage }\end{array}$ & $5 \cdot 3$ & 0.9 & 0.84 \\
\hline $\begin{array}{l}\text { 'Convenience' } \\
\text { Is easy to prepare } \\
\text { Can be cooked very simply } \\
\text { Takes no time to prepare } \\
\text { Can be bought in shops close to where I live or work } \\
\text { Is easily available in shops and supermarkets }\end{array}$ & $5 \cdot 0$ & $1 \cdot 1$ & $0 \cdot 78$ \\
\hline $\begin{array}{l}\text { 'Natural content' } \\
\text { Contains no additives } \\
\text { Contains natural ingredients } \\
\text { Contains no artificial ingredients }\end{array}$ & $4 \cdot 8$ & $1 \cdot 2$ & 0.77 \\
\hline $\begin{array}{l}\text { 'Weight control' } \\
\text { Is low in calories } \\
\text { Helps me control my weight } \\
\text { Is low in fat } \\
\text { Is low in sugar }\end{array}$ & $4 \cdot 5$ & $1 \cdot 1$ & 0.73 \\
\hline $\begin{array}{l}\text { ‘Mood' } \\
\text { Helps me cope with stress } \\
\text { Cheers me up } \\
\text { Makes me feel good }\end{array}$ & $4 \cdot 3$ & $1 \cdot 3$ & 0.73 \\
\hline $\begin{array}{l}\text { 'Price' } \\
\text { Is not expensive } \\
\text { Is cheap } \\
\text { Offers good value for money }\end{array}$ & $4 \cdot 3$ & $1 \cdot 2$ & 0.65 \\
\hline $\begin{array}{l}\text { 'Ethical concerns' } \\
\text { Has the country of origin clearly marked } \\
\text { Is packaged in an environmentally friendly way }\end{array}$ & $4 \cdot 3$ & $1 \cdot 4$ & 0.55 \\
\hline $\begin{array}{l}\text { 'Familiarity' } \\
\text { Is what I usually eat } \\
\text { Is familiar } \\
\text { Is like the food I ate as a child }\end{array}$ & $4 \cdot 0$ & $1 \cdot 2$ & 0.55 \\
\hline
\end{tabular}

'Natural content' has emerged as relatively important in recently published studies ${ }^{(21,24,25)}$. The latter may be due to increased concern among consumers regarding the use of artificial additives in foods and drinks.

Given the intense focus on dieting and weight control by health authorities and the media in recent years, it seemed likely that the food choice motive 'weight control' would have a relatively high importance. However, 'weight control' was not among the four most important parental motives defined in the present study. One possible explanation may be, as suggested by others ${ }^{(21)}$, that parents consider weight control to be less important when focusing on the family diet than when focusing on their personal diet.

The importance of 'price' as a motive factor for food choice has previously been highly ranked in several studies, especially among low-income groups ${ }^{(8,10,15)}$. In the present study, however, 'price' was among the motives considered least important by parents. This may partly be explained by Norway's high standard of living and high wage levels, which mean that only about $10 \%$ of consumers' income is spent on food. Furthermore, most of the participants (89\%) in the present study fell into the two upper categories of family income.

All of the food choice motives included in the regression analysis were significantly associated with one or more of the eating patterns of the children (Table 3). The strongest associations were observed between the parental food choice motive 'health' and the 'varied Norwegian' eating pattern, and between the motive 'weight control' and the 'dieting' pattern.

Children with parents who rated 'health' as important scored highly on the 'varied Norwegian' eating pattern and low on the 'junk/convenient' eating pattern, indicating 
a high intake of a diverse diet comprising regular meals and a low intake of high-energy foods and fast food. The observed associations are similar to those found in adult studies ${ }^{(10,38)}$ and among Finnish families ${ }^{(21)}$. Children with parents who considered 'weight control' important scored highly on the 'dieting' pattern and low on the 'junk/convenient' and 'snacking' patterns, although no significant association was observed between 'weight control' and the 'varied Norwegian' eating pattern. The results indicate that parental weight concerns may be a promoter to a high intake of 'light' products rather than the recommended diverse diet.

We have previously reported that adherence to the 'varied Norwegian' eating pattern was favourable in maintaining normal weight status and achieving a change from overweight to normal weight in children, compared with adherence to the 'dieting' pattern ${ }^{(28)}$. Moreover, dieting behaviour and strict food restrictions have been associated with overweight in children and adolescents in other studies ${ }^{(39-41)}$. The present results emphasise the importance of focusing on parents' health concerns, rather than their weight concerns, when promoting healthy eating by children. Furthermore, the present results indicate that 'natural content' may promote the 'varied Norwegian' eating pattern and be a barrier to the 'dieting' eating pattern, a finding similar to associations found among Finnish families ${ }^{(21)}$. Hence, highlighting the importance of natural ingredients and low additive content could be an additional way to encourage parents to purchase recommended foods for their children.

The motive 'convenience' was associated with high scores for the 'junk/convenient' eating pattern and low scores for the 'varied Norwegian' eating pattern, indicating that parents consider healthy foods to be less accessible and more time-consuming and difficult to prepare. The results suggest that 'convenience' may act as a barrier to recommended foods and regular meals and as a promoter to easily accessible, quick 'junk' foods. Fast food purchases for family meals in busy families and high availability of unhealthy food at home have previously been associated with high intakes of such foods among adolescents ${ }^{(42,43)}$. Furthermore, the idea that healthy foods and meals are generally difficult to prepare is likely to be common among many consumers ${ }^{(31,44)}$. To improve children's diet, health authorities should strive to make healthy food more easily available, develop new products that are easy to prepare, and make families with children aware of easy ways to prepare healthy food.

'Sensory appeal' was the most important parental motive for food choice overall, but was only associated with the children's 'dieting' pattern. The lack of association with the other eating patterns indicates that sensory quality is important across most food types ${ }^{(10)}$.

The parental motive 'mood' was positively associated with the two unhealthy eating patterns 'snacking' and 'junk/convenient'. The 'mood' motive contains items 
related to emotional state, relaxation and stress control, and the results suggest that this may have a stronger association with recreational and emotional eating than with the basic diet and everyday food.

The present study has strengths, but also limitations that should be recognised. One strength is the large sample of respondents and the relatively high response rate. Furthermore, the study included several background variables considered important with regard to diet and food choice motive variability. Another strength of the study is the use of PCA-derived eating patterns as a measure of the children's overall dietary and meal habits, as opposed to individual nutrients, single food items, single meals or indices containing just a few indicators of a healthy or unhealthy diet ${ }^{(45)}$. The present FFQ represented a wide range of commonly used food items, snack products, drinks and meals, resulting in robust factors (eating patterns) that all include multiple items.

The FCQ used in the present study was modified to make the parents focus on the family's diet rather than their own preferences. We used thirty-two of the thirty-six original statements, and added one new statement. The initial PCA defined underlying dimensions comparable to those defined by the original $\mathrm{FCQ}^{(8)}$ and only minor deviations were observed. Consequently, we used the original dimensions to calculate food choice motives, as they are easy to interpret and have been found valid and reliable in other samples. This may have caused weaker correlations between food choice motives and diet data than if dimensions based strictly on the current PCA had been used. Furthermore, the internal reliability of the calculated motives was somewhat lower than in the original $\mathrm{FCQ}^{(8)}$ and in the modified FCQ used in six European countries $^{(31)}$, possibly due to the modifications described. Nevertheless, the motives used in the regression analyses had acceptable internal reliability $(\operatorname{Cr} \alpha \geq 0 \cdot 70)^{(35)}$.

We had previously collected parent-reported dietary data on the same children at age $9-10$ years $^{(27)}$. The present study was a follow-up, and parental reporting was chosen to avoid differing data collection conditions at the two collection times, and to reduce under-reporting, which is thought to be common among adolescents ${ }^{(46)}$. We cannot exclude the possibility that the dietary reports were influenced by parental under-reporting of unhealthy items or over-reporting of healthy products, as parents are probably less aware of what their children eat outside the home ${ }^{(46)}$. Further, biases caused by errors in memory cannot be excluded $^{(47)}$. Consequently, it is likely that the dietary data reflect the parents' 'dietary image' rather than the true habitual diet of the children ${ }^{(47)}$. The current FFQ data were used to derive dietary patterns which reflect dietary behaviour. Dietary patterns are less likely to be distorted by misreporting than estimated intakes of energy, nutrients and food amounts. The reproducibility and validity of PCA-derived dietary patterns assessed using FFQ have previously been found to be comparable to those of patterns obtained by weighed dietary records ${ }^{(48-50)}$. Any parental misreporting of food items is likely to have attenuated the association between food choice motives and eating patterns.

Parents may over-report socially acceptable motives ${ }^{(21)}$. Therefore, we cannot exclude the possibility that some parents answered the questions with their personal food preferences in mind. However, the FCQ was presented to the parents after the FFQ, and the introduction to the statements was modified to make the parents focus on the family's diet rather than their own preferences. This is likely to have helped the parents keep the family diet in mind when reporting their food choice motives.

It can be assumed that social background and family weight status may have influenced the parental food choice motives and the children's eating habits ${ }^{(8,11,12,20)}$. Clear associations have previously been reported between eating patterns and parental education levels, maternal overweight and the tracking of children's overweight ${ }^{(27,28)}$. However, the observed associations between food choice motives and eating patterns remained almost unchanged when adjusted for the background variables, indicating an important independent association, also observed by others $^{(21)}$. It should be noted that self-reported weight is prone to under-reporting. This may have biased the effect of parental BMI categories in the adjusted models.

It should be recognised that in the present study the food choice motives explained only part of the variation observed in the children's dietary data. Children's eating patterns may be influenced by other factors inside and outside the home, like television advertisements, peers, etc. Furthermore, the FCQ reports the food choice motives of individuals, a limited part of the complex range of factors related to food choice ${ }^{(9)}$. The present study's crosssectional design eliminates the possibility of identifying causal relationships between parental food choice motives and children's eating patterns.

Another possible limitation is bias due to missing data. However, as complete data were obtained for more than $70 \%$ of the respondents, and because those with missing data did not differ substantially from the rest in terms of available background variables, we consider this problem to be limited. The data collection was undertaken in one Norwegian county only and the results are not necessarily representative of the national population. Furthermore, the participating parents had a somewhat higher education level and total family income than the Norwegian population in general.

\section{Conclusions}

The parental motive 'sensory appeal' emerged as the most important overall motive for food choices concerning the family's daily diet, followed by the motives 'health', 'convenience', 'natural content' and 'weight control'. 
All food choice motives included in the regression analysis were significantly associated with one or more of the child eating patterns. The motive 'health' was the parental food choice motive which was most strongly associated with a varied diet and regular meals, while the motive 'convenience' appeared to be an important barrier in this regard.

The results indicate that parental food choice motives may have important implications for the diet of children. To help and stimulate parents to make healthy food choices, health promotion activities targeted at families with children should focus on the health benefits and naturalness of recommended foods, a varied diet and regular meals, rather than emphasising weight control. In order to increase the intake of healthy foods by children, authorities should strive to make a diverse selection of healthy foods easily available, stimulate the development of new, healthy products which are easy to prepare, and make families with children aware of easy ways to prepare healthy food.

\section{Acknowledgements}

Sources of funding: This research was supported by Telemark University College, Telemark Hospital, the Research Council of Norway and the Public Health Programme for Telemark. Conflicts of interest: The authors declare no conflict of interest. Authors' contributions: I.M.O and M.V.S. were responsible for the study design and data collection. M.V.S. was responsible for the statistical analyses. M.H. provided the Norwegian version of the FCQ and all authors contributed to the interpretation of results. I.M.O. drafted the manuscript and M.H. and M.V.S. revised it critically. All authors read and approved the final version of the manuscript. Acknowledgements: The authors appreciate the cooperation of the children and their parents, the faculty and staff of the Telemark County primary and lower secondary schools, and the public health nurses who participated in the study. They would like to thank Dr Anne Lise Brantsæeter, Norwegian Institute of Public Health, for useful comments on the manuscript.

\section{References}

1. World Health Organization (2003) Diet, Nutrition and the Prevention of Chronic Diseases. WHO Technical Report Series no. 916. Geneva: WHO.

2. World Health Organization (2003) Global Strategy on Diet, Physical Activity and Health. Geneva: WHO; available at http://www.who.int/dietphysicalactivity/en/

3. Reilly JJ \& Kelly J (2011) Long-term impact of overweight and obesity in childhood and adolescence on morbidity and premature mortality in adulthood: systematic review. Int J Obes (Lond) 35, 891-898.

4. Samdal O, Leversen I, Torsheim T et al. (2009) The Health Behaviour in School-Aged Children: WHO Collaborative Cross-National Study (HBSC). Bergen: Norwegian Research Centre for Health Promotion, The University of Bergen.
5. Andersen LF, Lillegaard IT, Overby NC et al. (2005) Overweight and obesity among Norwegian schoolchildren: changes from 1993 to 2000. Scand J Public Health 33, 99-106.

6. Juliusson PB, Eide GE, Roelants M et al. (2010) Overweight and obesity in Norwegian children: prevalence and sociodemographic risk factors. Acta Paediatr 99, 900-905.

7. Fotopoulos C, Krystallis A, Vassallo M et al. (2009) Food Choice Questionnaire (FCQ) revisited. Suggestions for the development of an enhanced general food motivation model. Appetite 52, 199-208.

8. Steptoe A, Pollard TM \& Wardle J (1995) Development of a measure of the motives underlying the selection of food the food choice questionnaire. Appetite 25, 267-284.

9. Eertmans A, Baeyens F \& Van den Bergh O (2001) Food likes and their relative importance in human eating behavior: review and preliminary suggestions for health promotion. Health Educ Res 16, 443-456.

10. Pollard TM, Steptoe A \& Wardle J (1998) Motives underlying healthy eating: using the food choice questionnaire to explain variation in dietary intake. J Biosoc Sci 30, 165-179.

11. Steptoe A \& Wardle J (2001) Motivational factors as mediators of socioeconomic variations in dietary intake patterns. Psychol Health 14, 391-402.

12. Crossley ML \& Khan SN (2001) Health promotion: motives underlying food choice: dentists, porters and dietary health promotion. Br Dent J 191, 198-202.

13. Pollard J, Kirk SFL \& Cade JE (2002) Factors affecting food choice in relation to fruit and vegetable intake: a review. Nutr Res Rev 15, 373-387.

14. Pollard J, Greenwood D, Kirk S et al. (2002) Motivations for fruit and vegetable consumption in the UK Women's Cohort Study. Public Health Nutr 5, 479-486.

15. Carrillo E, Varela P, Salvador A et al. (2011) Main factors underlying consumers' food choice: a first step for the understanding of attitudes toward 'healthy eating'. J Sens Stud 26, 85-95.

16. Faith MS, Scanlon KS, Birch LL et al. (2004) Parent-child feeding strategies and their relationships to child eating and weight status. Obes Res 12, 1711-1722.

17. Rossi A, Moreira EAM \& Rauen MS (2008) Determinants of eating behavior: a review focusing on the family. Rev Nutr 21, 739-748.

18. Scaglioni S, Salvioni M \& Galimberti C (1999) Influence of parental attitudes in the development of children eating behaviour. Br J Nutr 99, Suppl. 1, S22-S25.

19. Birch LL (1999) Development of food preferences. Annu Rev Nutr 19, 41-62.

20. Birch LL \& Davison KK (2001) Family environmental factors influencing the developing behavioral controls of food intake and childhood overweight. Pediatr Clin North Am 48, 893-907.

21. Roos E, Lehto R \& Ray C (2012) Parental family food choice motives and children's food intake. Food Qual Prefer 24, 85-91.

22. Marquis M \& Shatenstein B (2005) Food choice motives and the importance of family meals among immigrant mothers. Can J Diet Pract Res 66, 77-82.

23. Eertmans A, Victoir A, Notelaers G et al. (2006) The Food Choice Questionnaire: factorial invariant over western urban populations? Food Qual Prefer 17, 344-352.

24. Januszewska R, Pieniak Z \& Verbeke W (2011) Food choice questionnaire revisited in four countries. Does it still measure the same? Appetite 57, 94-98.

25. Hersleth M, Næs T, Rødbotten M et al. (2012) Lamb meat importance of origin and grazing system for Italian and Norwegian consumers. Meat Sci 90, 899-907.

26. Johansen SB, Naes T \& Hersleth M (2011) Motivation for choice and healthiness perception of calorie-reduced dairy products. A cross-cultural study. Appetite 56, 15-24. 
27. Oellingrath IM, Svendsen MV \& Brantsaeter AL (2010) Eating patterns and overweight in 9- to 10-year-old children in Telemark County, Norway: a cross-sectional study. Eur J Clin Nutr 64, 1272-1279.

28. Oellingrath IM, Svendsen M \& Brantsaeter AL (2011) Tracking of eating patterns and overweight - a follow-up study of Norwegian school children from middle childhood to early adolescence. Nutr J 10, 106.

29. Brislin RW (1970) Back-translation for cross-cultural research. J Cross Cult Psychol 1, 185-216.

30. Maneesriwongul W \& Dixon JK (2004) Instrument translation process: a methods review. J Adv Nurs 48, 175-186.

31. Pieniak Z, Verbeke W, Vanhonacker F et al. (2009) Association between traditional food consumption and motives for food choice in six European countries. Appetite 53, 101-108

32. Schelling AB \& Streitlien A (2007) Utprøving av spørreskjema 'Kostholds- og maltidsmonster, fysisk aktivitet og vektutvikling' (Pilot study of the questionnaire 'Diet and eating patterns, physical activity and weight development). Notodden: Telemark Educational Research.

33. Cole TJ, Flegal KM, Nicholls D et al. (2007) Body mass index cut offs to define thinness in children and adolescents: international survey. BMJ 335, 194.

34. Cole TJ, Bellizzi MC, Flegal KM et al. (2000) Establishing a standard definition for child overweight and obesity worldwide: international survey. BMJ 320, 1240-1243.

35. George D \& Mallery P (2011) SPSS for Windows Step by Step: A Simple Guide and Reference 18.0 Update. Boston, MA: Allyn \& Bacon.

36. Cattell RB (1966) The scree test for the number of factors. Multivariate Behav Res 1, 245-276.

37. Prescott J, Young O, O'Neill L et al. (2002) Motives for food choice: a comparison of consumers from Japan, Taiwan, Malaysia and New Zealand. Food Qual Prefer 13, 489-495.

38. Sun YHC (2008) Health concern, food choice motives, and attitudes toward healthy eating: the mediating role of food choice motives. Appetite 51, 42-49.
39. Neumark-Sztainer D, Wall M, Haines J et al. (2007) Why does dieting predict weight gain in adolescents? Findings from Project EAT-II: a 5-year longitudinal study. J Am Diet Assoc 107, 448-455.

40. Field AE, Austin SB, Taylor CB et al. (2003) Relation between dieting and weight change among preadolescents and adolescents. Pediatrics 112, 900-906.

41. Clark HR, Goyder E, Bissell P et al. (2007) How do parents' child-feeding behaviours influence child weight? Implications for childhood obesity policy. J Public Health 29, 132-141.

42. Boutelle KN, Fulkerson JA, Neumark-Sztainer D et al. (2007) Fast food for family meals: relationships with parent and adolescent food intake, home food availability and weight status. Public Health Nutr 10, 16-23.

43. Vereecken C, Haerens L, De Bourdeaudhuij I et al. (2010) The relationship between children's home food environment and dietary patterns in childhood and adolescence. Public Health Nutr 13, 1729-1735.

44. Almli VL, Verbeke W, Vanhonacker F et al. (2011) General image and attribute perceptions of traditional food in six European countries. Food Qual Prefer 22, 129-138.

45. Hu FB (2002) Dietary pattern analysis: a new direction in nutritional epidemiology. Curr Opin Lipidol 13, 3-9.

46. Livingstone MB \& Robson PJ (2000) Measurement of dietary intake in children. Proc Nutr Soc 59, 279-293.

47. Drewnowski A (2001) Diet image: a new perspective on the food-frequency questionnaire. Nutr Rev 59, 370-372.

48. Khani BR, Ye W, Terry P et al. (2004) Reproducibility and validity of major dietary patterns among Swedish women assessed with a food-frequency questionnaire. J Nutr $\mathbf{1 3 4}$, 1541-1545.

49. Hu FB, Rimm E, Smith-Warner SA et al. (1990) Reproducibilty and validity of dietary patterns assessed with a foodfrequency questionnaire. Am J Clin Nutr 69, 243-249.

50. Togo P, Heitmann BL, Sorensen TIA et al. (2003) Consistency of food intake factors by different dietary assessment methods and population groups. BrJ Nutr $\mathbf{9 0}$, 667-678. 